\title{
Redesign of Layout Runner in Rubber Injection Molding for Filling of a Multi-cavity Mold
}

\author{
LESLIE SANCHEZ-CASTILLO ${ }^{1}$, DORIAN NEDELCU², \\ MISAELA FRANCISCO-MARQUEZ ${ }^{1}$ \\ ${ }^{1}$ Instituto Politécnico Nacional, Unidad Profesional Interdisciplinaria de Ingeniería y Ciencias Sociales Administrativas, Av \\ Té 950, Col. Granjas México, CP. 08400, México City, México \\ ${ }^{2}$ Babes-Bolyai University, Faculty of Engineering, 1 Mihail Kogalniceanu Str., 400084, Cluj-Napoca, Romania
}

\begin{abstract}
This study presents a Solidworks ${ }^{\circledR}$ Plastics application in a company in the Automotive Industry for the aftermarket of auto parts manufactured by the injection molding process, the focus is on the redesign of an injection vein plate for achieve uniform filling of a 16 cavity mold with a geometry made up of a mixture of natural rubber and two metal components. This work proves that the use of symmetrical commands is not always the best option. The distances between runners were not taken into account as a source of the future wears problems in the mold. A layout is created with a combination of $2 D$ and $3 D$ sketches by turning the injection chanels $180^{\circ}$ in the problem cavities to increase the distances between runners and the filling of the 16 cavities is verified by simulation. It is also demonstrated by simulation that increasing the injection point size is not necessarily always the best option for cavity filling.
\end{abstract}

Keywords: rubber, runner, layout, Solidworks ${ }^{\circledR}$ Plastics, cavity

\section{Introduction}

Nowadays the automotive industry needs tools that allow design and do the processes more efficient, reducing cost and waste to offer better prices to different customers. Among these tools CAD applications can simulate the process before creating physical parts, which can significantly reduce the cost of raw materials. One of this tools is SolidWorks Plastic that helps in early stages of the injection process design to predict defects and make decisions that best suits the development of a tooling such as an injection mold, since the correct design of a mold represents a reduction in costs, time and waste by making the necessary modifications in 3D environments before bringing them to reality, in addition to avoiding rework [1].

In the market there are several applications for injection molding simulation such as Moldex3D, Sigma Sorfy®, Moldflow, however the use of Solidworks is enhanced by its easy environment and the possibility of developing custom materials, since in the automotive industry the used rubber mixtures are usually developed by the company.

Nowadays injection molding is the most used process in the manufacture of molded products. More than a third of thermoplastics materials are manufactured in injection machines [2]. The injection molding cycle begins when the mold closes and then the polymer is injected into the cavity through the runner system and the injection point [3].

In the automotive industry, the manufacture of rubber auto parts must be cared for under controlled parameters, normally these parameters are declared in a set-up, the process must have the ability to control these parameters such as pressure, temperature, filling time, vulcanization time, etc [4].

In the injection molding process one of the main challenges is the design of molds; multiple cavities molds are usually made of $2,4,8$ or 16 cavities following the $2 \mathrm{n}$ rule [5]. The mold plate need to have a good distribution of the injection chanels layout, a theme better known as "runner design", in which it will always be sought to guarantee a uniform filling of the cavities.

\footnotetext{
*email: dorian.nedelcu@ubbcluj.ro
} 
The distribution of the injection chanels in the molds tends to be of various types, depending on the number of cavities; their main function is to allow a balanced flow of the polymer in all cavities [6]; the injection chanels can be created by 2D or 3D sketch of lines and arcs [5], that connect with the cavities coincidentally. However is possible to use the wizard runner to create the layout, tool that does not need to create a sketch previously [3]; nevertheless this tool it is limited to the type of distribution.

The distance from the injection point to the gate location, which is the access point to the cavity, is one of the most important points to take into account in the design of runner layout; theoretically, the more symmetrical is the runner layout the filling of the cavities tends to be at the same time; also, the minimum length of the runner must be equal to ten times, its cross section and the size of the runner must decrease progressively from the primary injector to the gate location, it must be at least $15 \%$ less than the primary one [6]. The injection point (s) must be positioned near the center of the geometry to balance the filling of the cavity [3]; depending on the number of injection points, the locations will be selected for the flow inlet.

In the injection molding process, the mold is one of the main components, which do not necessarily consist of two parts (core and cavities) and depends largely on the geometry, the process and the machine; for the geometry studied in this article, the mold consists of seven plates, since it contains a system of intermediate drive punches.

Among the most common defects in injection molding process are the lack of filling of cavities, air traps, welding lines [6], but the lack of filling is usually associated with multiple factors, such as temperature in the mold, the melting temperature of the material or a poor distribution of injection chanels. The aforementioned phenomena can be simulated by means of CAD software under the finite element method (FEM) [7].

\section{Materials and methods}

\subsection{Current situation}

The molds created for rubber injection processes are normally made of multiple plates as shown in Figure 1, one of which corresponds to the injection-chanels as can be seen in Figure 2; generally injection molds have a long useful life depending on the material. In the case of the present study, the mold was created from A36 steel; it is known from experience and internal company records that the useful life of an injection mold is estimated at around 50 years, however this after a few years of use (13th year of work) a problem appear consisting in fissures and cracks in areas where the injection channels were placed at very short distances as can be seen in Figure 3 in the layout distribution; also, filling problems will begin to appear in two specific cavities, as is illustrated in Figure 4. This problem was attributed to the cracks that were created with the demand for the tooling and the years of use, although these were few. The lack of attention to the design of the in-mold injection chanels for rubber led the designer to create a plate that with the demand of use would be affected long before its estimated life time.

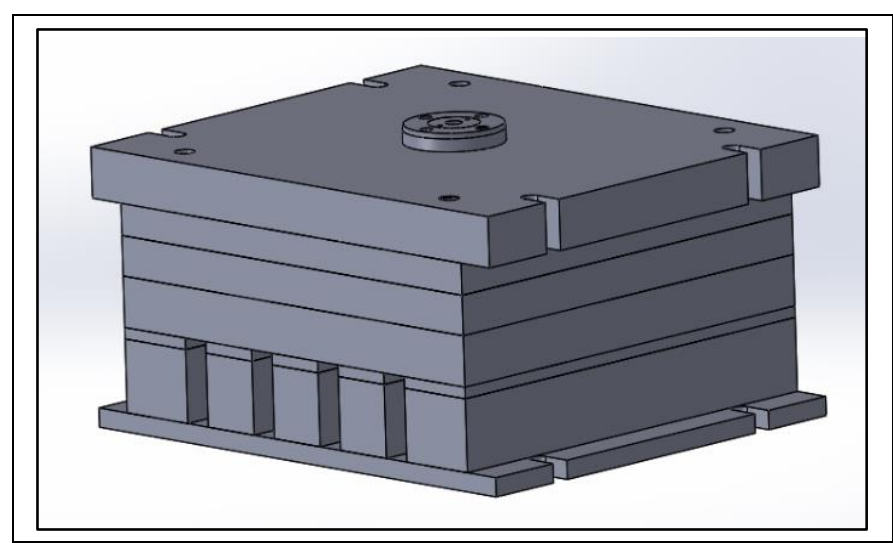

Figure 1. Injection mold

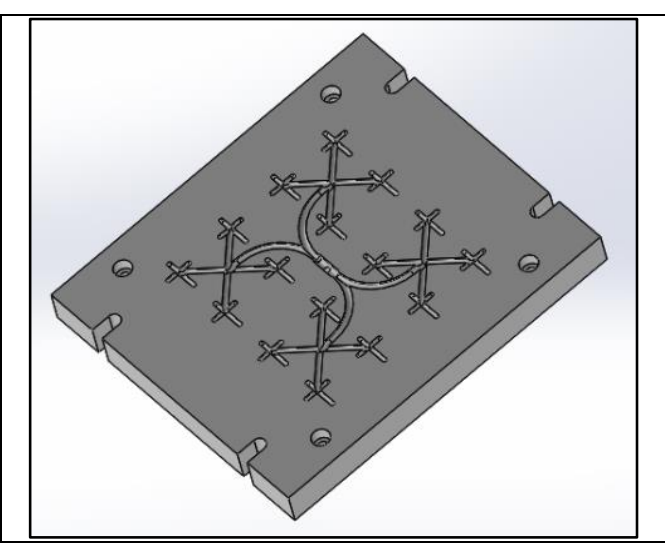

Figure 2. Injection chanels plate 
The injection vein plate has undergone rework such as welding points, but they have not been enough to counteract the problem, which has a direct impact on production levels; since the product corresponds to the high-volume for the aftermarket, this is created in a sixteen cavity injection mold with a vulcanization time of $350 \mathrm{~s}$. But the cavities associated with these veins frequently present defects of lack of rubber filling, so it is decided to cancel them instead of generating defects; at the same time, two pieces are no longer generated in each vulcanizing cycle, which corresponds to 154 pieces in a work $\operatorname{shift}(7.5 \mathrm{~h})$.

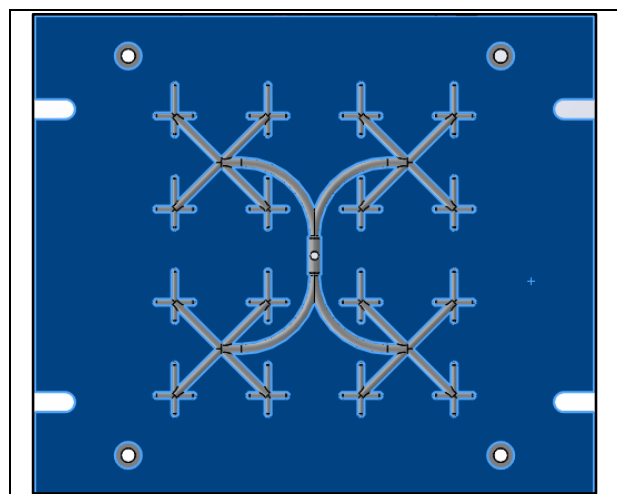

Figure 3. Injection runner layout

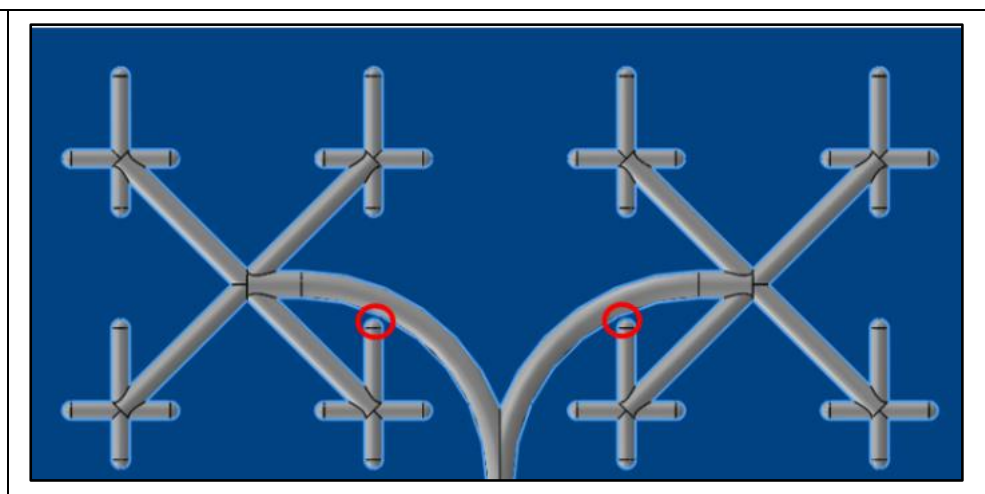

Figure 4. Injection chanels associated with the problem

When a vulcanizing cycle ends, the mold opens to be able to remove the pieces; likewise the rubber that remains in these injection vein channels must be removed, which is shown in Figure 5, colloquially known as "rubber spider"; it can be seen in Figure 6 that the injection chanels that leads to the cavity where the reworking of the rubber occurs, there is a detachment of material, associating defects such as the lack of rubber in these cavities.

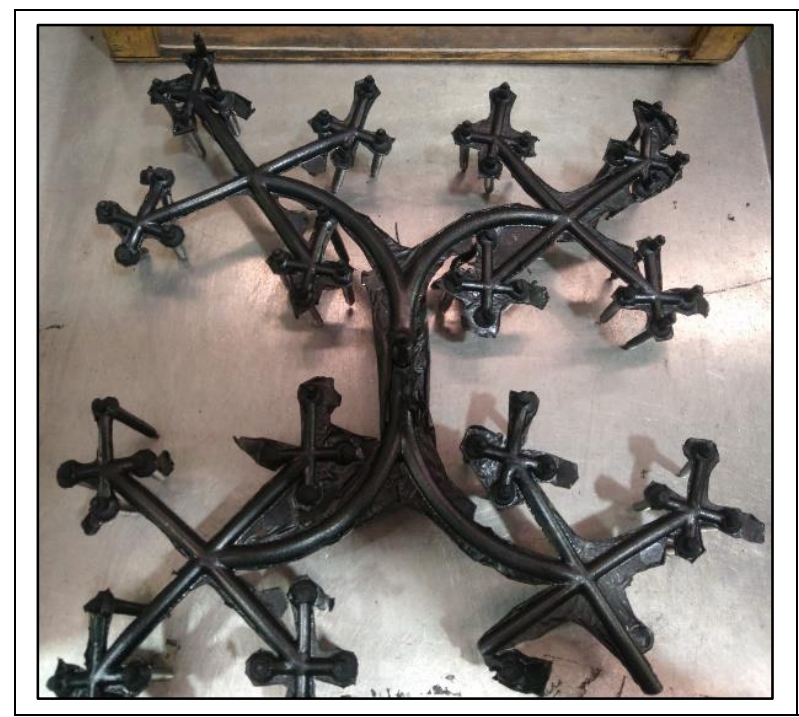

Figure 5. Rubber spider

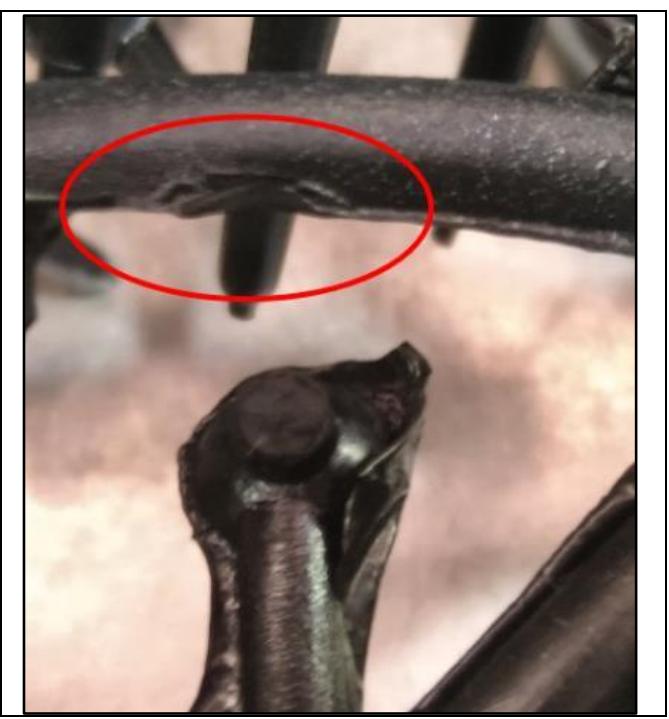

Figure 6. Damaged injection chanels

The quality of a product made by injection molding depends largely on the material and the process parameters [7]; ensuring that the cavities fill from the sprue evenly is an issue that concerns the injection chanels and the diameter of the injection point must be controlled. Due to the nature of the material used it is important to control this size; the material used in the process was configured as a custom material in Solidworks ${ }^{\circledR}$ Plastics. In the simulations, it represents a mixture of natural rubber produced by the company used for the aftermarket, following the ASTM D1418 and ASTM D-2000 AA standards for natural rubber, for which the material parameters are described in the Table 1; the theoretical data for 
this material were taken from the "Rubber Division" [8], direct readings from the injection machine which corresponds to a vertical Rutil; the Young's modulus, Poisson's Radius and density were obtained experimentally.

The experimental data of this work, were obtained in the internal laboratory of the company, for the Young's module a tensile test was carried out by means of a tensiometer "tensi TECH" model 11428, for the Poisson Radius a test of Tension paused before reaching the rupture to verify the deformation of the test tube and, for the density of the compound, it was carried out by means of an analytical balance.

Table 1. Material parameters

\begin{tabular}{|c|c|c|}
\hline Parameter & Value & Origin \\
\hline Melt temperatura & $70{ }^{\circ} \mathrm{C}$ & Machine readout \\
\hline Mold Temperature & $165^{\circ} \mathrm{C}$ & Machine readout \\
\hline Part ejection temperatura & $50{ }^{\circ} \mathrm{C}$ & Machine readout \\
\hline Glass Transition temperatura & $-65^{\circ} \mathrm{C}$ & Teoretical RD \\
\hline Specific Heat & $1100 \mathrm{~J}(\mathrm{~kg}-\mathrm{k})$ & Teoretical RD \\
\hline Thermal Conductivity & $0.13 \mathrm{~W} /(\mathrm{m}-\mathrm{k})$ & Teoretical RD \\
\hline Thermal Expansion Coefficient & 0.00000666 & Teoretical RD \\
\hline Elastic Moduls & $0.0359 \mathrm{MPa}$ & Experimental \\
\hline Poisson's ratio & 0.4161 & Experimental \\
\hline Density & 1.266 & Experimental \\
\hline
\end{tabular}

\subsection{The geometry}

The geometry in question represents a motor mount made of rubber-metal components like in Figure 7 , the natural rubber its main ingredient and the metal corresponds to an SAE1006 steel.

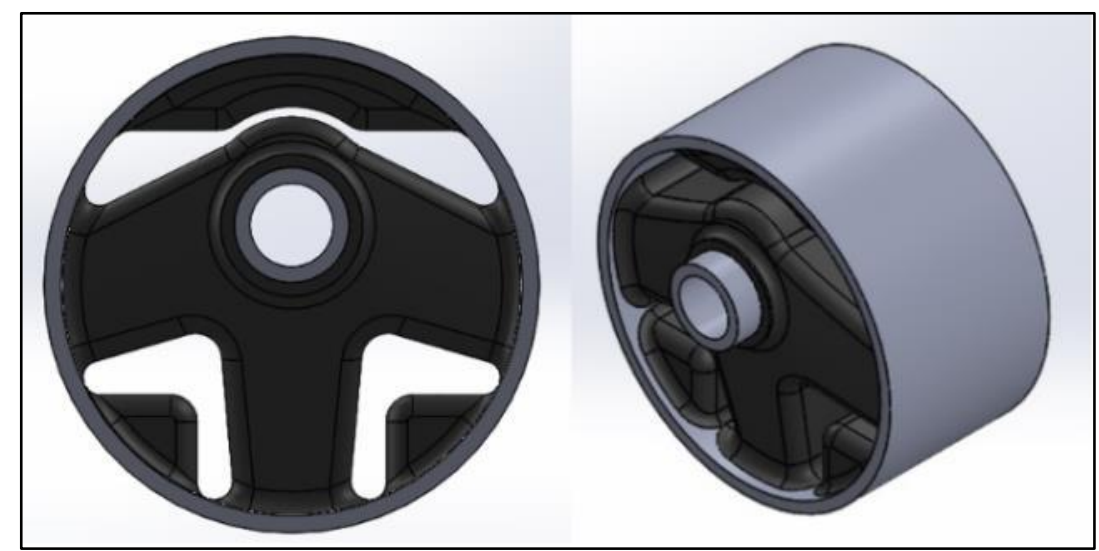

Figure 7. The geometry front and isometric view

\subsection{Proposed solution by SW}

Using CAD software, it is increasingly easier to check a process in a simulation before carrying it out with physical materials [9], which reduces machining times and costs; a simple solution is presented in the redesign injection chanels using Solidworks ${ }^{\circledR}$ Plastics.

Figure 8 shows the current distribution of the injection chanels. The proposed solution consists in turning the problem cavities with $180^{\circ}$ in order to widen the area between runners in the veins involved as shown in Figure 9, to prevent them from re-presenting cracks or details related to the previous problem. Currently, each cavity has four injection points of $2 \mathrm{~mm}$ each. For reasons associated with the production demand, it was proposed in the first instance to add more injection points; however, this would generate a return to the initial problem, even making it worse, when noticing that there was more than one crossing in the injection chanels (Figure 10) Therefore, it was only treated with two different sizes of diameter in the injection points, the original of $2 \mathrm{~mm}$ and an additional one of $2.5 \mathrm{~mm}$. 


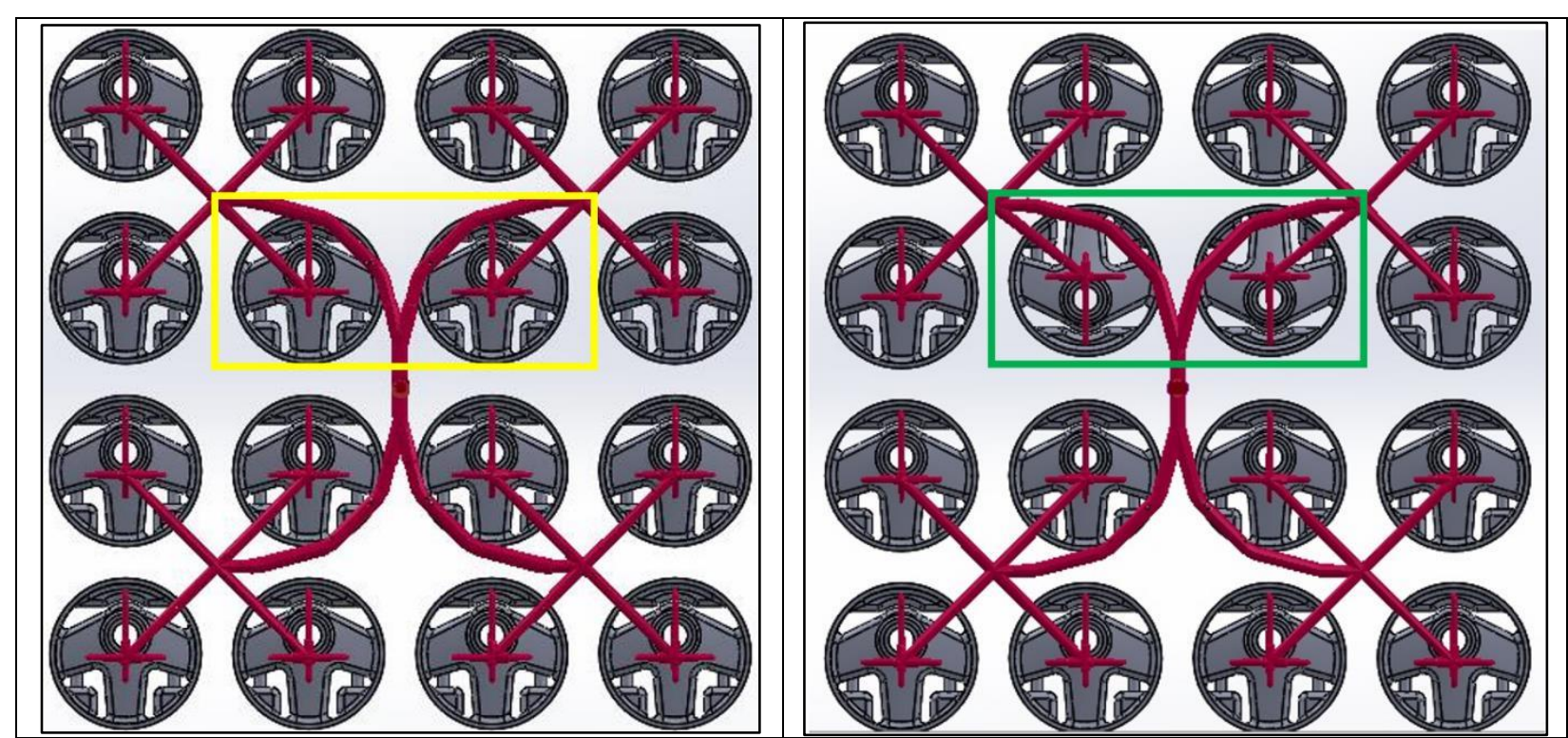

Figure 8. Current layout

Figure 9. Proposal layout

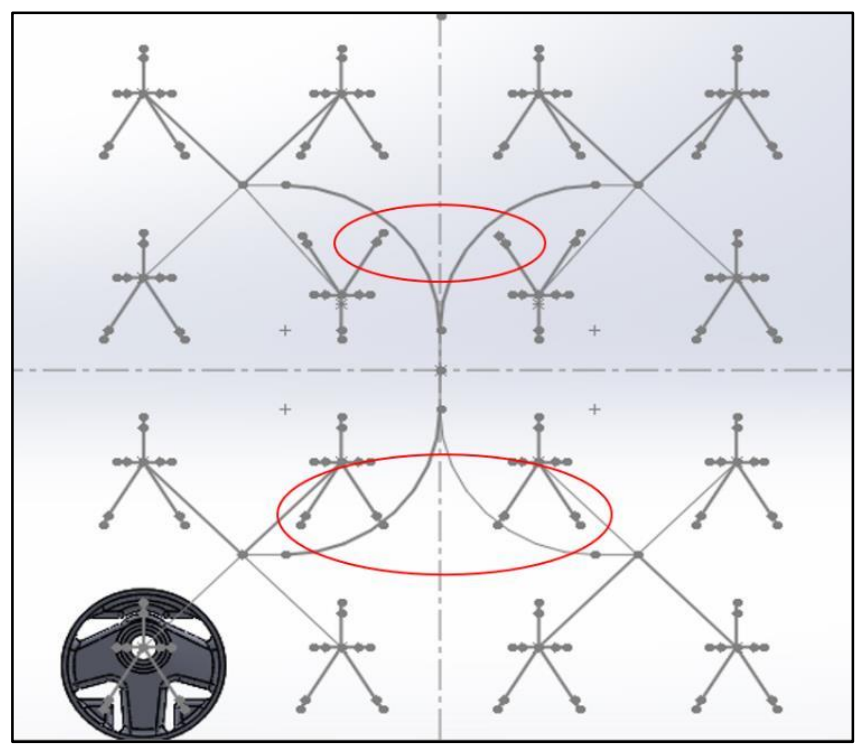

Figure 10. Proposal with 5 injection points (failed)

\subsection{Simulation}

The first step to perform a simulation in Solidworks ${ }^{\circledR}$ Plastics is to create the mesh of the geometry; the smaller size of the triangles is chosen the greater elements will be created for the simulation [10], which also represents greater computational resources. The mesh in this case was created in a solid mesh manual as shown in Figure 11 (mesh size of $2 \mathrm{~mm}$ ) with tetrahedral elements, resulting in a total of 152,870 elements and 47.076 nodes, the injection chanel system was created for one cavity and, for the representation of the mold in the 16 cavities with the proposed shape, Figure 12 shows half of this design with a mesh size of $2.5 \mathrm{~mm}$. The injection chanels were created manually with a $3 \mathrm{D}$ sketch for the case of one cavity and, a combination of Sketch 2D and 3D for the case of sixteen cavities. 


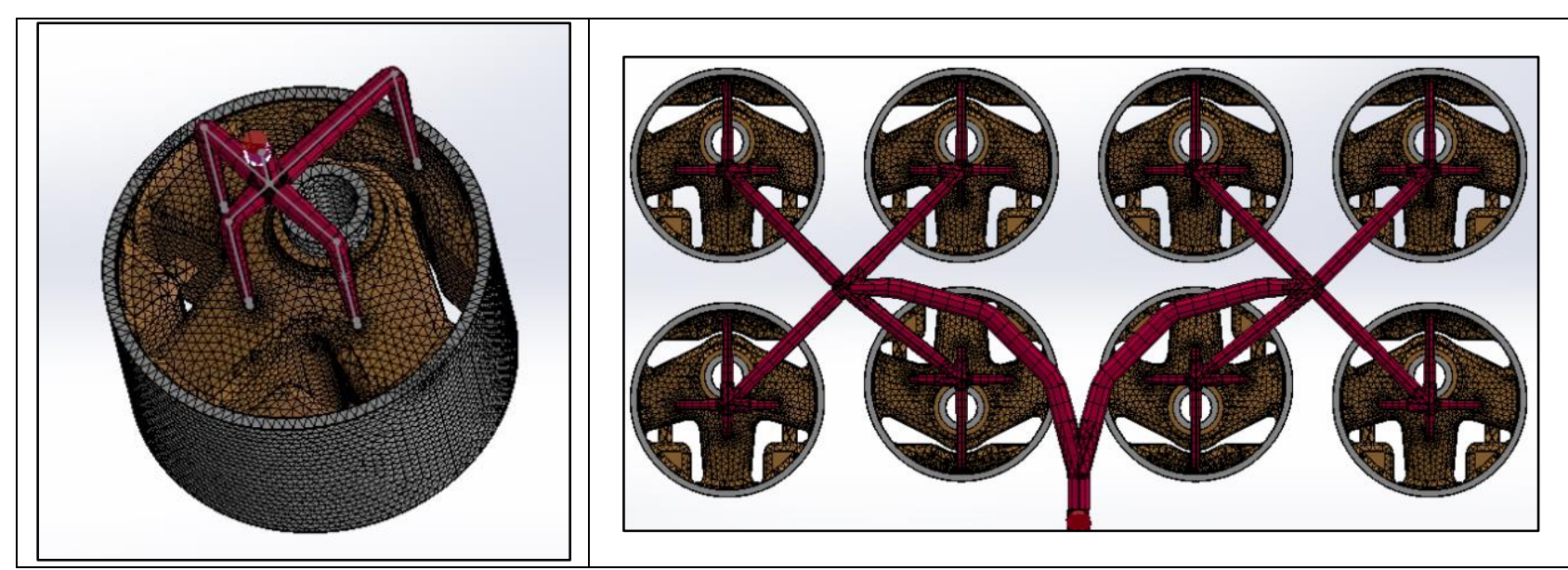

Figure 11. Solid mesh one cavity

Figure 12. Solid mesh in half layout

\section{Results and discussions}

The fill time results of the simulations calculated in Solidworks ${ }^{\circledR}$ Plastics are presented in the Table 2 ; for the injection points the mesh was of the solid type for both cases, in $2.0 \mathrm{~mm}$ and $2.5 \mathrm{~mm}$; it was observed that the increase in the diameter at the injection point it is not significant in the filling speed; due to the work involved in machining an injection mold plate it is not recommended increase this diameter. The real current fill time in the cavity is $40 \mathrm{~s}$, which is close with the simulation time.

Table 2. Fill time

\begin{tabular}{|c|c|c|}
\hline $\begin{array}{c}\text { Injection location } \\
\text { diameter }\end{array}$ & $\mathbf{2 . 0} \mathbf{~ m m}$ & $\mathbf{2 . 5} \mathbf{~ m m}$ \\
\hline Fill Time & $47.36 \mathrm{~s}$ & $47.44 \mathrm{~s}$ \\
\hline
\end{tabular}

The filling time in the case of the $2.0 \mathrm{~mm}$ diameter injection point is very similar to reality, so the results are trusted.

The runner layout remained as originally designed except for the $180^{\circ}$ rotation in the problem cavities. Table 3 shows the distances in the designs of the channels of the current injection chanels (Figure 13), proposed (Figure 14) and in the lower part without affectation (Figure 15); highlighting the increase in the layout proposed in the affected area to ensure that injection vein plate problems do not recur.

Table 3. Difference in areas between runners

\begin{tabular}{|c|c|c|c|}
\hline & Current & Proposed & $\begin{array}{c}\text { Bottom layout } \\
\text { (unaffected) }\end{array}$ \\
\hline Left Layout & $6.88 \mathrm{~mm}$ & $\mathbf{3 5 . 6 5} \mathbf{~ m m}$ & $40.42 \mathrm{~mm}$ \\
\hline Right layout & $6.96 \mathrm{~mm}$ & $\mathbf{3 5 . 5 9} \mathbf{~ m m}$ & $40.24 \mathrm{~mm}$ \\
\hline
\end{tabular}

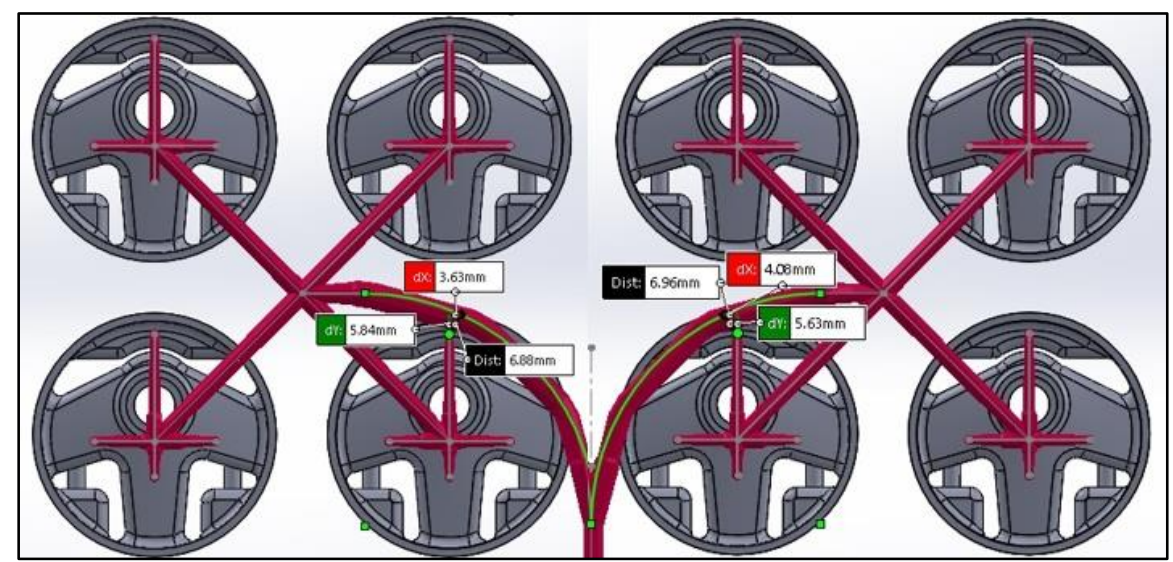

Figure 13.

Distance in current layout 


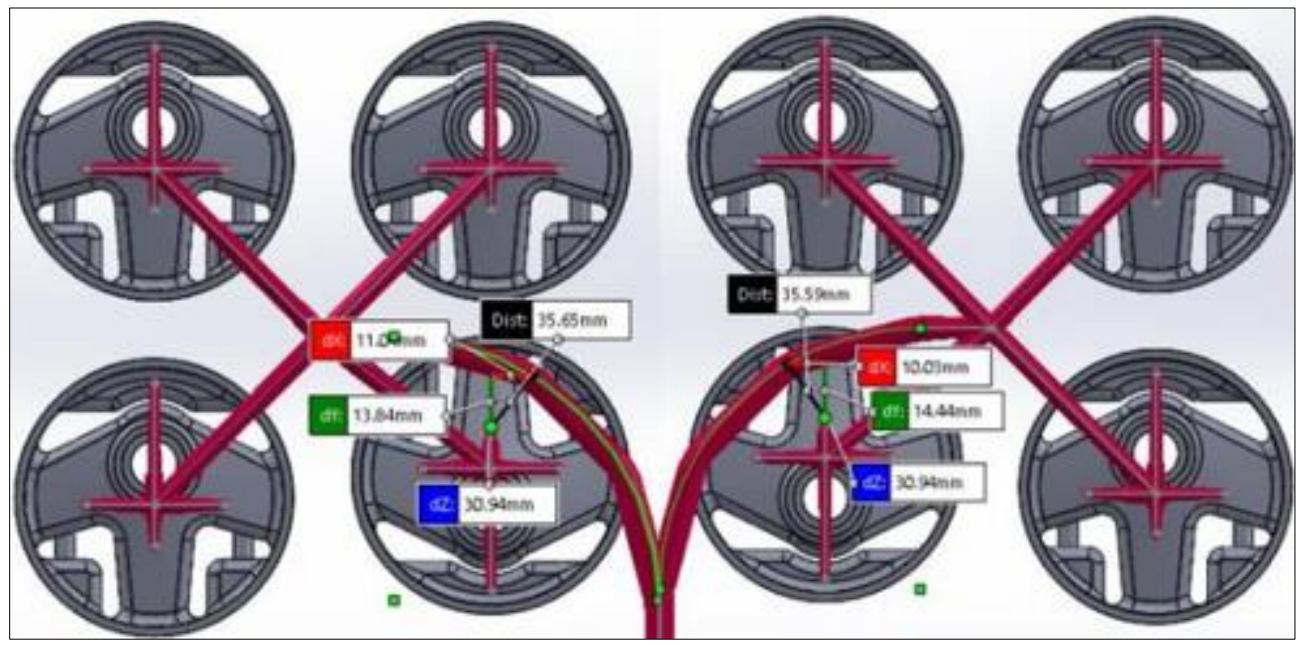

Figure 13. Distance between runner layout proposal

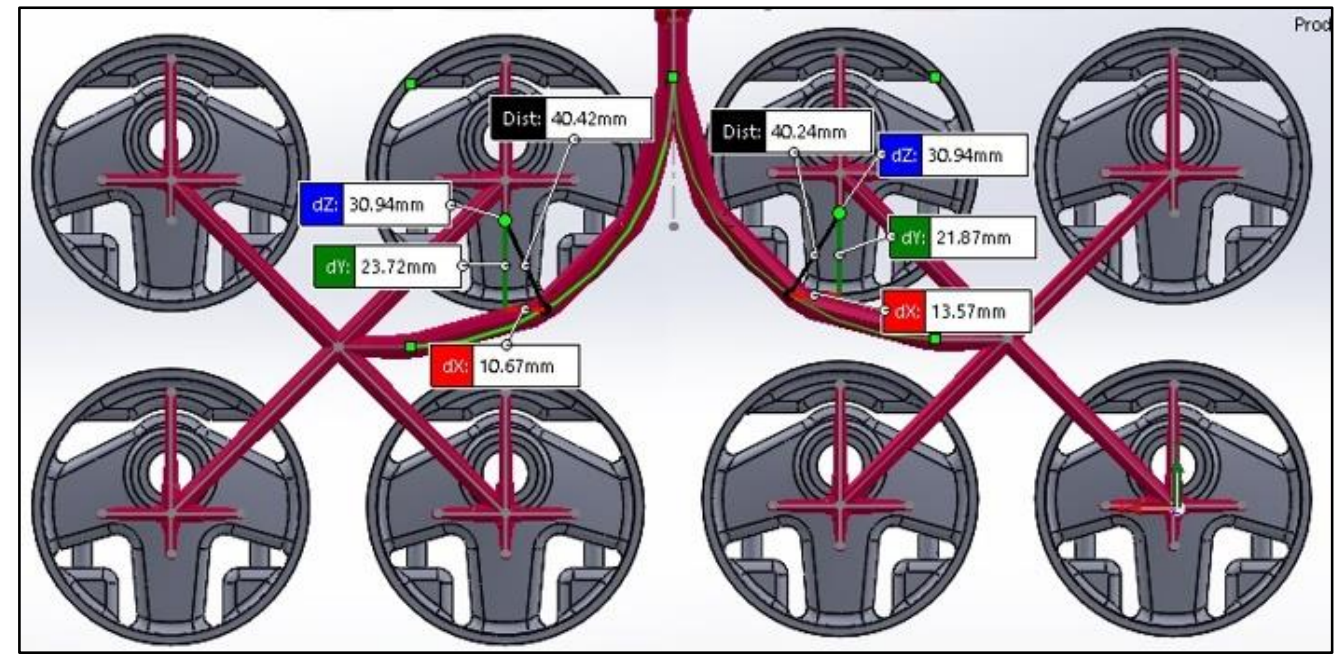

Figure 14. Bottom of the layout

The mold used for the molding of this part has a total of 16 cavities, the problem described presents the lack of filling of the compound in two cavities, which we intend to turn $180^{\circ}$ to correct these problems in the production area; this means that the current mold only has a production capacity limited to $87.5 \%$, with the proposed correction, productivity would increase by $12.5 \%$ allowing all the cavities to function, which would take full advantage of each molding cycle.

\section{Conclusions}

In the injection molding of multiple cavities, it is essential to create a mold that satisfies the requirements of simultaneous filling for all cavities; it is also important that the mold is designed to withstand the workload, considering materials and mold size. Sometimes it is very easy to use the symmetry commands in Solidworks without taking into account the conditions of the material with which it will be worked. The main contribution of the article is based on making the designer in the molded industry aware that not necessarily using symmetry is the best case in the machining of an injection mold, whether the distances between runners had been observed, this reworking of the injection chanels plate would have been avoided, which constitutes additional costs for the companies. The layout proposal in this article complies with the increase of the distance in the affected zone; the distances obtained are close to the distances in the zones where there is no problem in the runner layout; this decreases the possibility of the associated problem occurring again, likewise, the effectiveness of the filling of the 16 cavities in the injection mold was verified by simulation in Solidworks ${ }^{\circledR}$ Plastics to 
check the operation of the new layout. As Bernard Charles, CEO of Dassult Systemes says "Don't build anything physical until everything has been virtually proven", this phrase should be a practice that is fundamental throughout the manufacturing industry. As the databases for injection molding for rubber are scarce, the use of Solidworks ${ }^{\circledR}$ Plastics was taken as a reference base, the obtaining of variables of the custom material is highlighted since some values were obtained experimentally, by observation in the process and theoretical by the Rubber Division.

The impact on the company's productivity is the increase of $12.5 \%$, which contributes to the total use of the 16 injection mold cavities, the use of each molding cycle and the reduction of molding loads in the work shift, since for every 8 loads in the current mold (112 pieces), 16 pieces corresponding to one load are not being produced due to the lack of filling of two cavities.

\section{References}

1. DASSAULT SYSTEMES, Solidworks Plstics, Solidworks, 2018

2.C. FETECAU y F. STAN, Computational Prediction of Defects During Injection Molding in a Complex Part, Mater. Plast., 44(3), 2007, 180-184

3. M. KONSULOVA-BAKALOVA, Application of SolidWorks Plastic in the Training in Mechanical Engineering, Technical University of Varna (Annual Journal), vol. 1, $\mathrm{n}^{\mathrm{o}}$ 1, pp. 85-96, 2017

4. H. CIOBAN, L. BUTNAR C. GHITA, Studies Regarding Molding Process for Industrial Rubber Products, Mater. Plast., 49(3), 2012, 158-162

5.*** Dassult Systemes, Solidworks Plastics, 2020

6. G. A. COSCIA, Handbook for the use of rubber injection molding machines, Self published, 1998.

7. M. MOAYYEDIAN, K. ABHARY Y R. MARIAN, Improved gate system for scrap reduction in injection molding processes, Procedia Manufacturing, $\mathrm{n}^{\circ}$ 2, pp. 246-250, 2015

8. E. SHARP, Rubber Explained, [Webinar], Ed., 2020

9. ***Dassault Systemes, Las Simulaciones Precisas de Llenado de Moldes Resuelven los Problemas de Diseño y Produccion del Moldeado por Inyección, The 3DEXPERIENCE, 2016

10.*** Dassult Systemes, Solidworks Plastics Help 2017

Manuscript received: 5.05.2021 